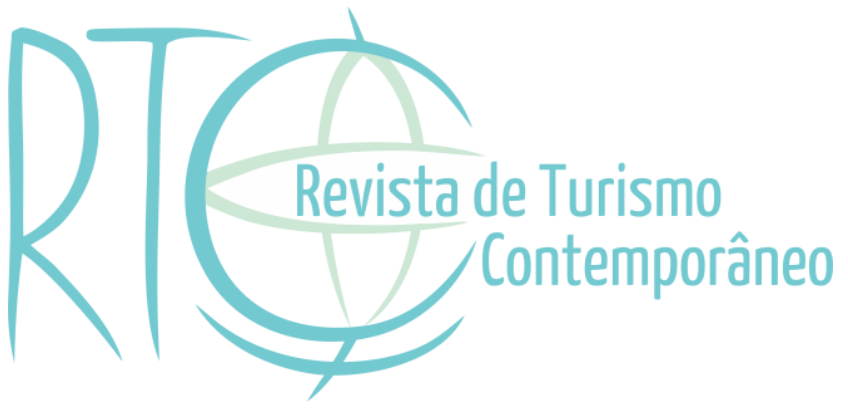

\title{
Agente versus estrutura no modelo multidimensional- reflexivo: estudo de caso de uma organização hoteleira do tipo cama café
}

Agent versus structure in the Multimensional-Reflective model: a case study of the organization thet is like the "Bed and Breakfast" hospitality

\section{Mariana Bueno de Andrade Matos}

Doutoranda em Administração pelo Programa de Pós-Graduação em Administração-PROPAD da Universidade Federal de Pernambuco-UFPE. Recife/PE, Brasil

E-mail: mbuenodeandrade@gmail.com

\section{Beatriz Gondim Matos}

Doutoranda em Administração pelo Programa de Pós-Graduação em Administração-PROPAD da Universidade Federal de Pernambuco-UFPE. Recife/PE, Brasil

E-mail: gm.beatriz@gmail.com

Maria de Lourdes de Azevedo Barbosa

Professora do Departamento de Hotelaria e Turismo/DHT e do Programa de Pós-Graduação em Administração/PROPAD da Universidade Federal de Pernambuco-UFPE, Recife/PE, Brasil E-mail: lourdesbarbosa@gmail.com 


\section{RESUMO}

O presente estudo teve como objetivo compreender o sistema organizacional de um meio de hospedagem do tipo Cama e Café a partir da relação agência/estrutura, ou seja, da relação entre as pessoas e a estrutura organizacional da empresa. A análise dessa relação buscou avaliar como esses elementos (agente e estrutura) se influenciam a partir do modelo Multidimensional-Reflexivo (Alves, 2004). Para tanto, buscou-se fundamentação na teoria de Weber, nomeadamente, os conceitos de Ação Social, Tipo Ideal e Estruturas puras de Dominação. Como metodologia, realizou-se um estudo de caso de natureza qualitativa de um meio de hospedagem do tipo Cama e Café. A coleta de dados se deu por entrevistas semiestruturadas, e as informações foram tratadas com a técnica de análise do discurso. Com o resultado da pesquisa verificou-se que existe a supremacia do agente sobre a estrutura na empresa e o subtipo em que se enquadra o „cama e cafée é o organizacional-administrativo patriarcal reformista, ou seja, em que o líder da empresa tem autonomia administrativa e é livre da tradição, e, assim, promove mudanças já que a coordenação e o controle são centrados nele.

Palavras-chave: Análise Organizacional. Modelo Multidimensional Reflexivo. Organização Hoteleira Cama e Café.

\section{ABSTRACT}

This study aimed to understand the organizational system of a Bed and Breakfast hospitality business from the relationship between agent/structure, therefore, the relationship between people and the organizational structure of the company. The analysis of this relationship aimed to evaluate how these elements (agent and structure) influenced each other from the Multidimensional-Reflective framework (ALVES, 2004). To this end, it sought justification in Weber's theory in particular the concepts of Social Action, Ideal Type and pure structures of domination. The method used is a qualitative case study of a Bed and Breakfast. The data collection was carried out by semi-structured interviews and the information is treated with the discourse analysis technique. With the result of the research it was found that there is the supremacy of the agent on the structure in the company and the subtype that fits the 'bed and breakfast' is the patriarchal organizational and administrative reform, in which the leader of the company have administrative autonomy and is free of tradition, and thus promotes changes since the coordination and control are focused on it.

Keywords: Organizational Analyses. Multidimensional-Reflective Framework. Bed and Breakfast Hospitality Organization. 


\section{INTRODUÇÃO}

A análise sociológica das organizações parte de diferentes ênfases analíticas. Um dos principais dilemas no campo é a escolha entre agência e/ou estrutura como unidade de análise. No entanto, recorrente aos estudos organizacionais, esta decisão parece sem solução por estar mais associada às escolhas ontológicas do pesquisador e ao conjunto do aporte teórico conexo do que uma evolução conceitual próxima de se solucionar (Reed, 2003).

Tentativas vem sendo feitas por estudiosos da área no sentido de diminuir esse conflito evitando a dicotomia analítica, com movimentos teóricos que têm gerado discussões importantes e resultado em alternativas de compreensão sobre a temática (Reed, 2003). O posicionamento destes teóricos parte de escolhas capazes de dar conta dos fenômenos sob uma visão mais relativista e integradora da análise agência/estrutura (Emirbayer \& Mische, 1998).

É sob uma abordagem analítica integradora que se situa o Modelo MultidimensionalReflexivo (OMR) de Alves (2004). Apresentado nos primeiros capítulos de seu livro

"Racionalidade, Carisma e Tradição nas Organizações Empresariais Contemporâneas", discorre sobre os seus fundamentos e toma como ponto de partida a teoria weberiana presente em "Economia e Sociedade" (Weber, 1999).

O modelo reconhece a presença da racionalidade instrumental associada ao desempenho técnico-econômico da organização - manifestada a partir da adequação entre meios e recursos em relação a determinados fins. Mas também identifica a presença de outros fatores no seio organizacional referenciadas pela subjetividade dos indivíduos (dos agentes): emoções, conflito e percepção afeta as relações, ao passo que, a subjetividade também é incentivada quando se trata da necessidade de vínculos de confiança. Logo, "o modelo considera que há sempre presente na empresa um certo grau de racionalidade instrumental ao lado de ingredientes tradicionais e afetivos em variadas intensidades" (Alves, 2004, p.97).

Alves (2004) baseou-se na teoria de Weber para o desenvolvimento do seu modelo Multidimensional-Reflexivo (OMR) de análise de organizações contemporâneas por este ser considerado um dos fundadores da sociologia moderna e por suas teorias serem robustas e influenciarem diversos estudos nas áreas de economia, filosofia, direito, ciência política e administração.

De acordo com Weber (1999), a construção teórica relativa à concepção dos tipos ideais, da ação social e das estruturas puras de dominação leva a duas situações 
organizacionais: a supremacia do agente ou a supremacia da estrutura. $\mathrm{O}$ agente sendo considerado as pessoas que formam a empresa, e a estrutura é o formato da instituição, seus processos e padrões organizacionais. Alves (2004), no entanto, ao desenvolver o modelo OMR, levou em conta que essas duas situações podem não ser antagônicas, apresentando possibilidades de combinações e variações na relação agente-estrutura.

Nos estudos organizacionais, a ênfase da análise organizacional com foco no agente parte do pressuposto de que o indivíduo não se submete às normas sem questioná-las, portanto, deve-se levar em conta as motivações do agente e as suas atitudes na organização. No outro extremo, tem-se a ênfase na estrutura, que incentiva, no sentido de facilitar ou restringir, a ação do indivíduo. Nesse caso, as regras e padrões influenciam fortemente as ações dos agentes (Alves, 2004).

Na busca por contribuir para uma melhor compreensão dessa relação agente-estrutura no âmbito de turismo optou-se por estudar uma organização do setor de hospedagem, do tipo „Cama e Caféee, localizado na cidade de Olinda, Pernambuco. Esse tipo de empreendimento é classificado no Ministério do Turismo como "hospedagem em residência com no máximo três unidades habitacionais para uso turístico, com serviços de café da manhã e limpeza, na qual o possuidor do estabelecimento resida" (Brasil, 2015, p. 1).

Considerado como um meio de hospedagem extra hoteleiro, o Cama e Café se caracteriza por ser uma empresa de pequeno porte, mas como um meio inovador e criativo na área de hotelaria (Beni, 2003; Giaretta, 2005; Pimentel, 2007), por essa razão despertou interesse das pesquisadoras para avaliação dos aspectos relativos à sua gestão e organização. Além disso, a organização escolhida reflete uma tendência no Brasil impulsionada com o incentivo para a formalização de pequenos negócios; instituído pelo artigo $3^{\circ}$, inciso II, da portaria 130 de 26.07.2011; o qual estabelece que o micro empreendedor individual pode solicitar cadastramento da atividade de meio de hospedagem tipo cama e café (Brasil, 2011). $\mathrm{O}$ incentivo legal motivou pequenos negócios como o analisado neste estudo a iniciarem um processo de formalização e passarem a compor um modelo emergente de organização na área de turismo.

Diante do exposto, o presente artigo tem como objetivo compreender o sistema organizacional de um meio de hospedagem do tipo Cama e Café a partir da relação agência/estrutura, tomando como base o modelo Multidimensional-Reflexivo (OMR). 


\section{FUNDAMENTOS DO MODELO MULTIDIMENSIONAL REFLEXIVO - OMR}

O modelo multidimensional-reflexivo (OMR) proposto por Alves (2004) parte da premissa de que as organizações são passíveis de serem analisadas com maior ênfase ou no agente ou na estrutura como uma decisão metodológica. Esse modelo considera que tanto o agente influencia a estrutura, como a estrutura possui força sobre o agente, assim, estes são reciprocamente condicionantes.

O modelo tem o objetivo de ser um meio de análise organizacional. Para isso, o OMR busca analisar as ações sociais dos agentes e da estrutura, que levam as organizações a serem enquadradas em determinados tipos ideias: racional, tradicional e carismático. Esses tipos ideias geram as estruturas puras de dominação de Weber (1999), que, por sua vez, dão origem aos tipos de gestão organizacional propostos do OMR. Tais perfis organizacionais podem ter ênfase na estrutura ou no agente. Os indicadores que podem ser utilizados para uma análise organizacional do modelo, sucintamente, são: o ambiente externo e relações interempresariais, características estruturais e dispositivos de coordenação, características do agente e relacionamentos internos e, por fim, o sistema técnico operacional. Esses conceitos serão discutidos com maior profundidade nos tópicos seguintes.

\subsection{TIPOS IDEAIS E AÇÃO SOCIAL}

Para apoiar o objetivo do estudo, explicitando melhor os construtos do artigo, neste tópico serão apresentados os conceitos de Tipos Ideal e Ação Social com base na teoria de Weber (1999). O conceito de tipo ideal é fundamental dentro da epistemologia de Weber (1999) considerando-se que a construção parcial da realidade é uma escolha do pesquisador. O tipo ideal é uma seleção arbitrária e, portanto, subjetiva das características de um fenômeno e deve ser utilizado para fins de reflexão e compreensão da uma dada realidade estudada (Alves, 2004).

Os tipos ideais ocorrem no pressuposto da existência de uma relação social que será motivada por uma ação social. A ação é toda conduta humana (ato, omissão, permissão) dotada de um significado subjetivo dado por quem a executa e que orienta essa ação e, pode ser: racional orientada aos fins, racional com relação a um valor, afetiva ou tradicional. A racional orientada aos fins ou instrumental é consciente, calculada e deliberada (orientada a alcançar através dos meios, os fins). A racional orientada a um valor é imbuída de fé, 
orientada e fundada em um critério superior inquestionável. Ação afetiva é determinada por estados emotivos temporários. E, por fim, a ação tradicional é estabelecida a partir de costumes consagrados no tempo.

Sobre o conceito de dominação, é importante diferenciá-lo do conceito de poder antes de seguir com os próximos itens desta seção. O poder, para Weber (1999), se caracteriza como a imposição da vontade de um sobre os demais e ocorre quando, possivelmente, utilizase de força coercitiva para isso. Já a dominação configura-se pela iniciativa da tomada das ações por parte de alguns (dominantes), e pela aceitação e legitimação de outros (dominados) ações. Essa relação é, portanto, pacífica e aceita por ambas as partes.

É importante perceber que a ação social será a responsável pela condução do formato de gestão para cada um dos tipos ideais: racional, carismático ou tradicional. Esses tipos ideais dão origem à estruturas de dominação puras, que, quando combinadas, dão origem a diferentes formas modos de gestão e formatos organizacionais. Neste artigo estão sendo estudadas as proposições de combinações de Alves (2004) em seu Modelo Multidimensional Reflexivo. Tais maneiras de gestão, que podem ser baseadas na estrutura ou no agente, são o foco deste artigo, tal como foi explicitado na apresentação do objetivo do texto. O próximo tópico abordará os tipos puros de dominação conceituados por Max Weber.

\subsection{AS ESTRUTURAS PURAS DE DOMINAÇÃO DE WEBER}

Os tipos puros de dominação conceituados por Weber (1999) são três: o patriarcal, o carismático e o burocrático. A estrutura patriarcal de dominação é um importante princípio estrutural pré burocrático, e sua essência encontra-se na autoridade do chefe da comunidade doméstica baseada na santidade e na tradição dos senhores. Um exemplo de dominação patriarcal são os índios, que entendem que a pessoa mais velha é a mais sábia da aldeia e que, portanto, é a mais capacitada para comandar e tomar as decisões. Esse "respeito ao líder" é eternizado por meio das gerações, que obedecem ao cacique por tradição simplesmente.

Para Weber (1999) a dominação patriarcal e patrimonial é comparada algumas vezes com a estrutura burocrática, estabelecendo-se incongruências entre essas. Weber afirma que ambas se baseiam na autoridade e no cumprimento de normas, mas que a diferença está nas razões para o cumprimento e na natureza da criação das normas. Na dominação patriarcal, a criação de leis e o cumprimento destas são baseados no poder e respeito que os súditos têm por seus senhores. E isso se estabelece mediante uma relação de "pai" e "filho", que não necessariamente de sangue. 
A dominação carismática diz respeito a dominação exercida pelos "chefes naturais" (Alves, 2004, p. 31), ou seja, por um indivíduo que possui carisma e é legitimado pelos seus seguidores para realizar ações segundo sua própria convicção. O líder carismático não está subordinado a normas tradicionais ou regras juramentadas, e seu poder advém de características pessoais reconhecidas pelos seus seguidores. Exemplos citados são: o guerreiro, o herói, o profeta. Um fato interessante a ser destacado é o caráter interno da dominação carismática, ou seja, nela, os homens são transformados de "dentro para fora", e as revoluções e lutas são geradas de acordo com os interesses do líder (Alves, 2004).

O último tipo de dominação discutido por Weber, e também por Alves (2004) na parte de seu livro que dedica aos fundamentos de seu modelo, é a dominação burocrática ou racional. Esse tipo de dominação é, para Weber, a que "corporifica a racionalização" (Alves, 2004, p.35) e progressivamente se sobrepõe à ação afetiva ou à ação tradicional. Nesse sentido, a burocracia se baseia na legalidade, e, ao contrário das demais, nas relações impessoais e na formalidade: em leis, normas e regulamentos.

É nestes três tipos de dominação que se baseiam as proposições de análise da organizacional do Modelo Multidimensional Reflexivo, e no qual se baseiam este estudo. No próximo tópico serão apresentadas as diferenças das organizações que possuem ênfase no agente e aquelas que possuem ênfase na estrutura.

\section{3 ÊNFASE NA ESTRUTURA VERSUS ÊNFASE NO AGENTE}

Como dito anteriormente, a construção teórica que fundamenta o modelo Multidimensional Reflexivo (OMR) leva em conta que em uma organização pode-se dar ênfase ou ao agente ou à estrutura, sendo esta uma decisão metodológica.

Segundo Alves (2004), foi mediante situação de muitas greves nos Estados Unidos que pesquisadores começaram a observar o fator humano enquanto agente e central para os estudos organizacionais. É, então, por meio de sindicatos trabalhistas que os empregados começam a demonstrar resistência às práticas empresariais que privilegiam o sistema-empresa ao invés das pessoas. Foi nesse contexto que Hawthorne, Mayo e outros observaram que a atitude do empregado, a natureza dos grupos formados e os laços existentes entre as pessoas influenciavam no desempenho empresarial (Alves, 2004).

No outro extremo, tem-se a ênfase na estrutura, que estaria agindo no sentido de facilitar ou restringir a ação do indivíduo. Assim, "a teoria da estruturação procura escapar da 
polaridade do determinismo e da liberdade totais, e assume que há um conjunto de opões disponível para o exercício da ação em um conjunto de circunstâncias qualquer (Cohen apud Alves, 2004, p.56)". Com foco na estrutura, parte-se do pressuposto que as ações dos agentes são ordenadas por princípios, regras e padrões. Esse tipo de abordagem "é encontrado, por exemplo, no taylorismo, fordismo, fayolismo, contingencialismo, institucionalismo, e, em parte, pela abordagem pós modernista" (Alves, 2004, p.45).

Alves (2004) afirma que ao fim do século XIX, a produção industrial começa a exigir das organizações uma produção mais cheia de procedimentos e normas e profissionais especializados. É nesse contexto que nasce a abordagem clássica do taylorismo, o fordismo e o fayolismo dos estudos organizacionais. Nesses três exemplos citados a compreensão de organização é reduzida ao processo produtivo, e, por isso, indivíduos mantinham-se confinados em exercerem seus papéis e a adaptarem-se ao ritmo da máquina. É com essa base que nascem também o contingencialismo, o institucionalismo, e a indícios da abordagem pósmodernista.

Se retomadas as estruturas puras de dominação, associando-as às organizações, uma tentativa de aproximar o ideal ao real, três situações tendem a ser identificadas. No tipo de organização burocrática, a estrutura teria primazia sobre o indivíduo, sufocando sua autonomia através das regras e rotinas. No caso da carismática, a ênfase é no agente individual quando a organização é centrada no líder. E no contexto de uma organização patriarcal, a autonomia do agente, o patriarca, pode ser anulada em prol da tradição, ou pode ser flexível para realizar mudanças com o intuito de administrar o patrimônio.

Mas, de acordo com o próprio conceito de tipo ideal, as estruturas puras não representam a realidade empresarial. E sim, combinações dessas. Nesse contexto, Alves (2004) afirma que "o modelo multidimensional-reflexivo considera sempre presente na empresa um certo grau de racionalidade instrumental, ao lado de ingredientes tradicionais e afetivos em variadas intensidades".

Para aplicação do modelo, existem proposições básicas a serem adotadas na análise, quais sejam:

Em um contexto organizacional, a emergência de um líder empresarial com traços carismáticos decorre de um processo que integra as habilidades e a personalidade do líder, crenças ou objetivos compartilhados, o vínculo afetivo entre os integrantes da empresa e a interação destes com o líder Proposição E1 (Alves, 2004, p. 272)

O agente organizacional multidimensional-reflexivo (AMR) é um construto teórico indissociável do modelo e representa um indivíduo que age 
racionalmente em relação a fins, mas também orientado pela tradição e movido por sentimentos afetivos - Proposição E2 (Alves, 2004, p. 272)

Além de sua capacidade de liderança, a ação do agente é potencializada pelo seu estoque de conhecimentos e pela sua trajetória de sucesso - Proposição E3 (Alves, 2004, p. 272).

A partir das proposições relacionadas em seu OMR, Alves (2004) combina as formas de atuação do agente (conservador, transformador e adaptador) com a dinâmica interna do modelo (organização-interações-reordenamento) e propõe alguns tipos estruturais, que são: ordenativo, liberativo e equiparativo. Desse modo, o OMR dá origem a sete subtipos estruturais: (1) o equiparativo-adaptador; (2) o ordenativo-conservador; (3) organizaçãoadministrativa patriarcal conservadora; (4) a organização administrativa burocrática rígida; (5) a liberativo-transformadora; (6) a organizacional administrativa patriarcal reformista; e, por fim, a (7) organizacional-administrativa de base carismática.

Sendo assim, Alves (2004) propõe a existência de variados subtipos de estruturas a partir da teoria weberiana utilizada como fundamento na elaboração do seu modelo. Tendo sido concluída a seção que discutiu as bases teóricas deste artigo, no próximo item serão apresentados os procedimentos metodológicos que orientaram o desenvolvimento desta pesquisa a fim de atingir o objetivo do estudo.

\section{METODOLOGIA DA PESQUISA}

A natureza desta pesquisa é qualitativa, pois busca compreender de forma detalhada os significados e características situacionais apresentadas pelos sujeitos de pesquisa (Richardson, 1999). Complementando, Flick, Kardorff e Steinke (2004) colocam que a pesquisa qualitativa é um convite a descrever o mundo „de dentro para fora ${ }^{e e}$, por meio do ponto de vista dos participantes.

Nesse contexto, e tendo como base o objetivo da pesquisa, a perspectiva deste estudo é de natureza qualitativa. Com a adoção da vertente qualitativa e, por meio do corpus de pesquisa, se teve acesso a informações mais profundas e aproximadas da realidade estudada, ainda que seja sabido que a realidade em si não pode ser conhecida na sua totalidade, de acordo com os pressupostos assumidos (Creswell, 2010).

Apresentada a natureza da pesquisa, a estratégia que pareceu ser mais adaptada foi o estudo de caso. Segundo Stake (1994), o objetivo da realização do estudo de caso é compreender o que pode ser aprendido a partir de um caso especial. Complementando, Flick 
(2009) afirma que é importante que o caso selecionado seja significativo para a problemática envolvida. É, em suma, o estudo das particularidades e das complexidades de um caso singular e, por isso, os casos são estudados detalhadamente e são usadas diferentes formas de coleta de dados durante um período de tempo prolongado (Stake, 1994).

O caso estudado foi um meio de hospedagem do tipo cama e café localizado na cidade de Olinda-PE. O termo cama e café, tradução em português para o inglês bed and breakfast, surgiu na Inglaterra (Smith \& Smith, 2002). Na época, proprietários de mansões que passavam por dificuldades financeiras cobravam uma taxa por hospedagem com a finalidade de ampliar a renda. Durante a grande depressão americana esse sistema também se popularizou nos Estados Unidos. Atualmente, a rede americana Bed and Breakfast tem em torno de 475.000 propriedades rurais e urbanas cadastradas, tais empresas são casas de família, pousadas, cama e café, Guest Houses, chalés, hotéis históricos, pequenos resorts, fazendas de trabalho e Guest Ranches. Tais empreendimentos estão localizados em 120 países, incluindo o Brasil.

Os Cama e Café são meios de hospedagem extra hoteleiros (Beni, 2003) e/ou alternativos, essa denominação se dá pois complementam a oferta de leitos nos destinos turísticos, têm como característica serem mais econômicos do que os meios de hospedagem convencionais e apresentam uma grande variação quanto à sua prestação de serviços. Além disso, esses tipos de meios de hospedagem são de propriedade de pequenos empreendedores (Giaretta, 2005) e são em sua maioria de pequeno porte, possuindo estrutura de organização mais informalizada ou familiar, tendo em vista a sua própria natureza de negócio. Esse tipo de meio de hospedagem contribui de maneira efetiva para a inovação social do lugar e são importantes como uma alternativa de vida para a população local (Souza, Farina, Costa, Silva, \& Romeiro, 2014). São, portanto, importantes meios mais econômicos para os turistas e importantes empoderadores para a população local. São ainda, por suas características menos formais, importantes meios de interligação dos turistas com o meio, tornando o ambiente de hospedagem mais amigável e familiar (Souza et. al., 2014). Assim, os turistas e os proprietários do Cama e Café tendem a estabelecer uma relação de amizade em que os primeiros são orientados a respeito de passeios, restaurantes e tudo o que necessitarem (Cruz e Borges, 2006).

A empresa objeto deste estudo está há quatro anos em atividade e possui dois proprietários que são também cônjuges. Os dois são responsáveis por toda a gestão da empresa. Contam com o auxílio de apenas uma funcionária para a operação da empresa. Esse caso foi escolhido por ser o primeiro deste tipo na localidade e, portanto, pioneiro e mais 
amadurecido nesse tipo de empreendimento na região. A estrutura organizacional conta com dois proprietários líderes e uma funcionária subordinada a estes.

Em relação à coleta de dados, esta foi realizada por meio de entrevistas individuais semiestruturadas a partir de um roteiro com os dois gestores da organização. Essa técnica foi selecionada uma vez que se buscou obter informações mais aprofundadas, sendo, possivelmente, este o tipo de entrevista mais adequado.

Esse método foi escolhido com base em Flick (2009, p. 149), que defende que "os entrevistados possuem uma reserva complexa de conhecimento sobre o tópico em estudo" e é interessante que se consiga tornar explícito aquilo que está implícito. Como também em Bauer e Gaskell (2011, p. 65), na busca pela compreensão detalhada de crenças, atitudes, valores e motivações dos gestores em relação ao tema em estudo.

As entrevistas foram realizadas na organização estudada em horário determinado pelos gestores e duraram em torno de trinta minutos cada uma delas. Os dados coletados foram gravados com autorização dos entrevistados e posteriormente transcritos e analisados.

Os dados foram tratados por meio da técnica de análise do discurso que, segundo Parker (2004, como citado em Flick; Kardorff; Steinke, 2004), estuda o modo como os textos são construídos e os objetivos e contradições que fazem parte deste. Para Orlandi (1996), uma das primeiras estudiosas a trazer as discussões sobre a análise do discurso ao Brasil, esse método desperta a necessidade de interpretação de qualquer forma de discurso, levando em consideração os lugares, a forma, a natureza e o funcionamento deste.

A análise do discurso é, portanto, uma técnica que interpreta os dados de pesquisa levando em conta a linguagem e, junto a ela, a sociedade em que essa linguagem está inserida e o contexto ideológico envolvido. Não se pretende, portanto, instituir uma nova linguística, mas oferecer uma forma alternativa de análise, "lançar um olhar diferenciado sobre as práticas linguageiras" (Rocha; Deusdará, 2005, p. 308).

Quanto à aplicação da análise, o primeiro passo, e um dos mais importantes, é uma transcrição bastante detalhada das entrevistas. Essa etapa é fundamental para se conservar as características centrais da fala, e por isso a entonação, respiração, hesitação, interrupções, tudo deve ser anotado (Bauer; Gaskell, 2011). Tendo essas questões em mente, a etapa da transcrição foi realizada cuidadosamente no dia que seguiu as entrevistas. Todos os detalhes percebidos foram cuidadosamente transcritos

A codificação foi realizada como processo preliminar à análise e, para isso, as transcrições foram relidas diversas vezes, para, então, serem estabelecidos alguns padrões de 
discurso, de acordo com a linguagem e as relações sociais que o envolviam. As categorias utilizadas foram baseadas pelas questões de pesquisa, já que essa etapa é uma "maneira de organizar as categorias de interesse" (Bauer; Gaskell, 2011, p. 254). A última etapa foi a análise das categorias, na qual, Bauer e Gaskell (2011, p.255), colocam que o pesquisador deve buscar compreender as linguagens e os silêncios. Essa tarefa exigiu da pesquisadora sensibilidade, consciência e conhecimento prévios dos contextos sociais, políticos e culturais dos sujeitos de pesquisa.

\section{APRESENTAÇÃO E ANÁLISE DOS DADOS}

A análise dos dados foi baseada no objetivo deste estudo que buscou compreender o sistema organizacional de um meio de hospedagem do tipo Cama e Café a partir da relação agência/estrutura, tomando como base o modelo Multidimensional-Reflexivo (OMR). Dessa forma, a análise foi feita à luz das teorias em que este estudo se baseia e serão apresentadas neste tópico.

A partir das entrevistas realizadas, foi possível perceber que a empresa surgiu de maneira espontânea e por ideia de amigos, como informa o Entrevistado 1:

$\mathrm{Na}$ verdade, surgiu... (pausa) que a gente começou a receber amigos em casa. E, um desses amigos, um dia sugeriu... (pensando) eles são amigos que tem um „cama e cafée no Rio, em Santa Teresa, e eles acharam o local muito bom aqui. (Entrevistado 1).

Os dois gestores mantinham outras profissões e foram envolvendo-se com o Came e Café aos poucos, a medida em que ele foi crescendo e precisando de maior dedicação. A empresa hoje tem quatro anos de atividade e os dois gestores atualmente dão prioridade às atividades da empresa em detrimento de suas carreiras profissionais por formação (músico e professora). Os dois parecem muito felizes com o que houve, pois ao longo da entrevista demonstraram satisfação com o modo de vida, demonstraram também bastante prazer em receber pessoas em sua casa e manter uma relação saudável com os hóspedes. Percebeu-se que eles gostam e tratam os hóspedes como amigos e visitas pessoais, o que reforça a teoria defendida por Cruz e Borges (2006) e Souza et. al. (2014).

A venda dos dois quartos disponíveis no estabelecimento é realizada por meio de redes de hospedagem, principalmente o Trip Advisor e o AirBNB. É interessante para fins da análise estrutural desta empresa observar que são os próprios gestores que se comunicam com os 
possíveis hóspedes, e eles fazem uma "filtragem" de quem eles receberão. Dessa forma, percebe-se que eles selecionam quem eles querem receber e que, portanto, todo o processo de operação da empresa é centrado nos dois, como pode-se observar a partir da afirmação a seguir:

Me procuram muito do Booking [booking.com], mas o Booking e o Decolar eu não vou. Por que como eu falei, ali a pessoa faz a reserva sem me consultar [...]. E eu não quero isso. [...]Por que aí eu posso fazer um pequeno raio-x da pessoa. (Entrevistado 2)

Outro fator que corrobora para entender-se que toda a estrutura é centrada nos gestores, ou líderes, é que eles são responsáveis por muitas das atividades diárias da empresa e têm apenas uma funcionária. Essa funcionária é responsável pelas atividades de limpeza do Cama e Café e por auxiliar na preparação do café da manhã. No entanto, todas as coordenadas são dadas diretamente pela proprietária. Além disso, os gestores ao longo da entrevista relataram que a escolha por manter um meio de hospedagem desse tipo, em sua própria casa, se deu por ser parte de um estilo de vida escolhido por eles, tal como pode-se observar na afirmação que segue:

É nosso estilo de vida que eu não abro mão. (pensando) Eu já recusei propostas de trabalho que eu não topo, por que eu não quero. Eu quero morar num lugar que eu me sinta bem. Eu sei que muitas pessoas não têm essa chance, mas eu opto por isso. É isso, o nosso estilo de vida! (afirmação) Mas também não deixa de ser o meio de vida que eu também não vou subestimar, né? Assim, que financia a nossa vida.. (pausa) Eu vejo como trabalho. Quando eu sento aqui com os alemães é uma coisa muito prazerosa, mas também eu não vou subestimar isso. É meu trabalho. É uma coisa que eu gosto de fazer, mas é meu trabalho que faz parte do nosso pacote de atendimento. (Entrevistado 1)

Percebe-se também, que além do foco nos gestores, há um grande foco nos hóspedes, que são os clientes da empresa. Desde o café da manhã que é oferecido todos os dias até as atitudes dos gestores são bastante direcionadas ao que agradará os clientes. Um dos entrevistados ainda afirma que o único compromisso deles é com os hóspedes e com a sua satisfação.

Ainda de acordo com a última consideração do Entrevistado 1 citada, é possível nesse ponto perceber com clareza um trecho do que expõe Alves (2004,p.272) em sua teoria: "há sempre presente na empresa um certo grau de racionalidade instrumental, ao lado de ingredientes tradicionais e afetivos em variadas intensidade" . Nesse caso, percebe-se que embora ele esteja bastante envolvido afetivamente, a racionalidade também existe, já que embora ele goste e aproveite os momentos de conversa com os hóspedes, ele tem consciência 
de que naquela relação ele é o dono do empreendimento e o hóspede é seu cliente. Percebe-se então um alto grau de envolvimento afetivo, mas também existe de maneira equilibrada a racionalidade. Assim, confirma-se a Proposição E2, que afirma que o agente é um "indivíduo que age racionalmente em relação a fins, mas também orientado pela tradição e movido por sentimentos afetivos" (2004, p. 272).

Em outro momento da entrevista, a gestora cita duas situações de ênfase no hóspede:

O compromisso da gente com os hóspedes, se tornou um compromisso de servir bem. (Entrevistado 2)

A gente coloca dois tipos de pães na mesa: integral e branco. Pão de queijo, três frutas, queijo, presunto. (...) Então a gente já sabe o que o hóspede gosta. Se ele não come presunto, então no outro dia não vai. Então eu tenho que substituir a proteína, então amanhã você já não bota presunto, você já faz um ovo cozido ou então faz um ovo mexido, daí a gente observa.(pausa) Como é uma coisa pequena, a gente só tem dois quartos, você pode fazer isso. Uma coisa grande já não ia poder. Mas a gente dá essa atenção aqui. (Entrevistado 2)

Desse modo, percebe-se que há uma grande preocupação com as preferências e em agradar o hóspede, e por conta do pequeno tamanho da empresa, é possível ter esse cuidado e personalizar o serviço. Tal situação é conhecida pela proprietária e reconhecida pelos hóspedes, que avaliam muito bem os serviços nas redes sociais.

Por meio da entrevista, também percebeu-se que a proposição E1 de Alves (2004) encaixa-se na realidade estudada de maneira relevante. Tal proposição afirma que a emergência de um líder carismático integra as habilidades e a personalidade do próprio líder, as crenças e objetivos compartilhados com a empresa. Várias vezes foi possível perceber que as habilidades desenvolvidas pelos gestores do „cama e cafée muito tem a ver com o seu próprio modo de viver e suas características e aptidões pessoais. As tarefas são divididas de acordo com o que cada um sabe fazer melhor, e como eles moram também no mesmo local, a vida pessoal e a vida profissional da família se confunde, de certa forma, com a da empresa.

Do mesmo modo que a proposição E1, a proposição E3 também foi percebida pela pesquisadora ao longo das entrevistas. Tal proposição afirma que o estoque de conhecimentos e a trajetória de sucesso potencializam a ação do agente na empresa. Percebe-se que a vida anterior ao negócio dos gestores contribui para seu desempenho enquanto gestores. O líder da empresa é austríaco, e, por isso, sabe comunicar-se em alemão, inglês e francês e tem facilidade na negociação e prestação do serviço nesses idiomas. Já a sua esposa e também gestora, fala inglês e francês. Tais conhecimentos adquiridos anteriormente à existência do negócio são muito importantes para o dia-a-dia no trabalho. Tendo apresentado os resultados das entrevistas, a seguir serão tecidas as considerações finais. 


\section{CONSIDERAÇÕES FINAIS}

O presente estudo teve como objetivo compreender a estrutura de um meio de hospedagem do tipo Cama e Café a fim de perceber se há e de que modo opera a supremacia do agente sobre a estrutura organizacional no contexto de turismo. Ainda indicou-se que seria apontado o subtipo do modelo OMR em que melhor se enquadra a empresa analisada, de acordo com a teoria de Alves (2004).

Desse modo, a partir da análise dos resultados das entrevistas, observou-se que o subtipo em que se enquadra a empresa é o organizacional-administrativo patriarcal reformista, que "é um subtipo estrutural liberativo-transformador em que o patriarca se utiliza ao máximo de sua área de livre arbítrio" (Alves, 2004, p. 273).

A partir disso, e por ser um tipo liberativo-transformador, tem-se que existe sim uma supremacia do agente sobre a estrutura, tal como é indicado na teoria de Alves (2004, p. 131). Nesse subtipo, o liberativo-transformador, a empresa enfatiza a mudança, a flexibilidade, a originalidade e a inovação. Alves (2004) afirma ainda que esse subtipo existe quando há uma configuração organizacional-administrativa que decorre da combinação de componentes do patriarcado reformista e da liderança carismática. Características desse subtipo estão fortemente presentes na empresa analisada, já que ela acolhe fracamente componentes burocráticos, mas possui níveis de eficiência adequados aos meios e recursos direcionados aos seus objetivos. Para isso, utiliza-se de ingredientes tradicionais e carismáticos, sem deixar de existir um certo nível de racionalidade que permite a sua sobrevivência.

O desdobramento do subtipo liberativo-transformador a que melhor se enquadra a empresa é o patriarcal reformista. Duas das características do subtipo patriarcal reformista marcantes na empresa analisada são a valorização do livre-arbítrio do patriarca e a incipiência da burocracia. Por meio das entrevistas pôde-se perceber que o proprietário toma diversas decisões baseando-se em sua vontade e modo de ver o mundo. Além disso, não existem muitas regras e padrões na prestação de serviços e nos processos, tudo é realizado de acordo com a preferência dos hóspedes e dos gestores, de acordo com a necessidade do momento.

Sendo assim, acredita-se que o tipo de organização estudado é sim, não só do ponto de vista dos estudos em turismo, tal como afirmam Beni (2003) e Giaretta (2005), mas também 
do ponto de vista organizacional e administrativo, um meio de hospedagem que permite a criatividade e a inovação.

Acredita-se que esse tipo de meio de hospedagem pode ser rico para as localidades que buscam explorar o desenvolvimento de princípios de Economia Criativa e de Sustentabilidade na atividade turística local. Aparentemente, esse tipo de negócio pode ser importante para a geração de empregos e divisas em cidades turísticas, já que pode se tornar, como foi para a família proprietária da empresa estudada, um meio de vida.

Como limitação do estudo, sabe-se que a análise de apenas um meio de hospedagem é pouco para a generalização da teoria. No entanto, pelo próprio método e pressupostos assumidos, não tinha-se a pretensão de generalizar qualquer achado deste estudo. Seria interessante, portanto, que estudos quantitativos fossem feitos sobre o tema a fim de perceber se a realidade aqui encontrada acontece com frequência em outros Cama e Café brasileiros.

Tendo em vista que foi possível concluir neste artigo que as empresas do tipo Cama e Café são ambientes que permitem a criatividade, ainda sugerimos a pesquisadores futuros que busquem compreender melhor como se dão os processos de inovação nessas empresas e se os agentes estão inseridos/interessados em movimentos que os unam aos demais empreendedores da comunidade. Assim pode-se buscar compreender melhor como estas empresas individualmente contribuem para a localidade como um todo.

\section{REFERÊNCIAS}

Alves, Sérgio. (2004). Racionalidade, carisma e tradição nas organizações empresariais. Recife: ed. Universitária da UFPE.

Bauer, M.; Gaskell, G. (2011). Pesquisa Qualitativa com Texto Imagem e Som: um manual prático. (9a ed.) Petrópolis: Vozes.

Beni, M. C. (2003). Análise Estrutural do Turismo. São Paulo: SENAC.

Brasil. (2011).Portaria n ${ }^{\mathrm{o}} 130$ de 26 de Julho de 2011.

Brasil. (2015). Sistema Brasileiro de Classificação de Meios de Hospedagem. Recuperado em 15 de janeiro, 2016, de http://www.classificacao.turismo.gov.br/MTURclassificacao/mtursite/Entenda?tipo $=4$

Cohn, G. (1979). Crítica e resignação: fundamentos da sociologia de Max Weber. São Paulo: T. A. Queiroz.

Creswell, J. (2010) .Projeto de Pesquisa: métodos qualitativo, quantitativo e misto.(3a ed.) Porto Alegre: Artmed. 
Crozier, M. (1981). O fenômeno burocrático. (Cap. 6 e 7) Brasília: UNB.

Cruz, M. A. \& Borges, M. (2006). Os Meios de Hospedagem de Pequeno Porte de Águas de São Pedro (SP) e sua Importância para o Turismo Local. Turismo Visão e Ação. 8, (2), pp. 273-282.

Emirbayer, M., \& Mische, A. (1998). "What is agency?” American Journal of Sociology, 103(4), 962-1023.

Flick, U.; Kardorff, E.; Steike, I. (2004). A Companion to Qualitativa Research. London: Sage Publications.

Flick, U. (2009). Introdução à Pesquisa Qualitativa.( 3a ed.). Porto Alegre: Artmed.

Fontana, A. \& Frey, J. (2003). The Interview: from structured questions to negotiated text. In: N., Denzin, \& Y. Lincoln. Collecting and Interpreting Qualitative Materials. Thousand Oaks:London.New Dheli: Sage Publications.

Giaretta, J. M. (2005). Hospedagem Alternativa. In: Análises regionais e Globais do Turismo Brasileiro. Org. A.,Panosso Netto, M. Aldrigui, \& P. Pires. S. São Paulo: Roca.

Gil, A. C. (2009). Estudo de Caso. São Paulo: Atlas.

Gouldner, A. (1978). Conflitos na teoria de Weber. In: E.C.,COELHO. (Org.). Sociologia da burocracia (pp.59-67). Rio de Janeiro: Zahar.

Gusmão, L. de. (2000). A Concepção de causa na filosofia das ciências sociais de Max Weber. In: J. Souza (org.). A atualidade de Max Weber. Brasília: Ed. UNB.

Menezes, F. A. (2007). O universal pelo regional: política de Martins Filho para a Universidade Federal do Ceará. Monografia de Especialização. Universidade Federal do Ceará, Fortaleza, CE, Brasil.

Merquior, J. G. (1990). De Rousseau a Weber. Rio de Janeiro: Guanabara Koogan.

Mills, C. W. (1970). A imaginação sociológica. Rio de Janeiro: Zahar.

Motta, P.(1993). Gestão contemporânea: a ciência e a arte de ser dirigente. ( 3a ed.) (cap.3). Rio de Janeiro: Record.

Orlandi, E. P. (1996). Interpretação: autoria, leitura e efeitos do trabalho simbólico. Petrópolis: Vozes.

Pimentel, A. B. (2007). Hospedagem domiciliar na cidade do Rio de Janeiro: o espaço de encontro entre turistas e anfitriões. UFRJ.

Ramos, A. (1983). A administração e contexto brasileiro. Rio de Janeiro: FGV. 
Reed, M. (2003). The agency/structure dilemma in organization theory: open doors and brick walls. In H. Tsoukas \& C. Knudsen (Eds.), The oxford handbook of organization theory: meta-theoretical perspectives (pp. 289-309). New York: Oxford University press.

Richardson, A. (1999). Subjective Experience: Is Conceptual Status, Method of Investigation and Psychological Significance. The Journal of Psychology, 133 (5)

Rocha, D. \& Deusdará, B. (2005). Análise do Conteúdo e Análise do Discurso: aproximação e afastamentos na (re)construção de uma trajetória. Alea. 7, pp. 305-322.

Simon, H. (1965). Comportamento administrativo. Rio de Janeiro: FGV.

Smith, E. L \& Smith, A.K. (2002). A. Business management and marketing: bed and breakfast. Tourism Educational Materials. Michigan: Michigan State University Extension.

Souza, P.; Farina, M.; Costa, C.; Silva, A.; Romeiro, M.C. (2014). Relações Sociais no Setor Cama e Café em Parintins na Amazônia: Uma perspectiva com base nas análises de redes sociais. Revista Brasileira de Pesquisa em Turismo. 8, (1),pp. 145-160.

Stake, R. (1994). Case studies. In. N.,Denzin, \& Y., Lincoln. (Eds). Handbook of Qualitative Research. (pp.236-248).Thousand Oaks: Sage.

Stake, R. E. (1995). The Art of Case Study Research. London: SAGE Publications.

Udy, S. Jr., (1978). Burocracia e racionalidade na teoria weberiana de organização: um estudo empírico. In: $\quad$ E. C., Coelho, (Org.). Sociologia da burocracia. (pp.48-58). Rio de Janeiro: Zahar.

Vergara, S. C. (2003) Projetos e relatórios de pesquisa em administração.(4a ed.) São Paulo: Atlas.

Wber, M. (1982). Ensaios de sociologia. Rio de Janeiro: Guanabara

Weber, M. (1999) Economia e Sociedade. (Vol. 2). Brasília: UNB. 